\title{
Erratum to: Nestmate Recognition and the Role of Cuticular Hydrocarbons in the African Termite Raiding Ant Pachycondyla analis
}

\author{
Abdullahi A. Yusuf • Christian W. W. Pirk • \\ Robin M. Crewe • Peter G. N. Njagi • Ian Gordon • \\ Baldwyn Torto
}

Published online: 9 May 2010

(C) Springer Science+Business Media, LLC 2010

Erratum to: J Chem Ecol (2010) 36:441-448

DOI 10.1007/s10886-010-9774-6

In the original version of this article, some data on Table 1 were incorrect. The corrected Table is given below. The authors regret this error.

The online version of the original article can be found at http://dx.doi. org/10.1007/s10886-010-9774-6.

A. A. Yusuf · P. G. N. Njagi · I. Gordon · B. Torto ICIPE,

P. O. Box 30772-00100, GPO, Nairobi, Kenya

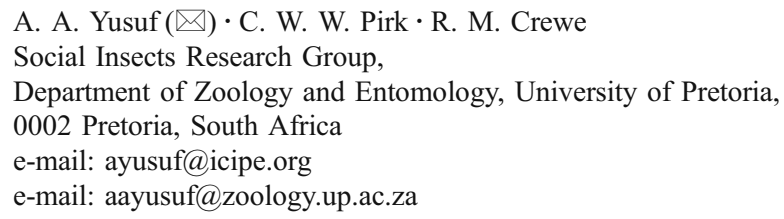


Table 1 Compounds identified from the cuticular hydrocarbon profiles of Pachycondyla analis, along with retention indices and diagnostic ions

\begin{tabular}{|c|c|c|c|}
\hline $\mathrm{No}^{\mathrm{a}}$ & Compound & $\mathrm{Ri}^{\mathrm{b}}$ & Diagnostic EI-MS ions (m/z) \\
\hline 1 & $n$-Octane & 800 & 114 \\
\hline 2 & $n$-Undecane & 1100 & 156 \\
\hline 3 & 5-Methylundecane & 1154 & $43,57,71,85,99,112$ \\
\hline 4 & 3-Methylundecane & 1169 & $43,57,71,85,99,112,141,170$ \\
\hline 5 & Unidentified & & \\
\hline 6 & $n$-Tridecane & 1300 & 184 \\
\hline 7 & $n$-Pentadecane & 1500 & 212 \\
\hline 8 & 3-Methylpentadecane & 1572 & $43,57,71,85,99,113,127,141,155,168,197,226$ \\
\hline 9 & 2-Methylheptadecane & 1765 & $43,57,71,85,99,113,127,141,155,169,183,195,211,239,254$ \\
\hline 10 & 1-Heptadecene & 1679 & $83,97,111,125,196,210,239$ \\
\hline 11 & 8-Heptadecene & 1679 & $41,55,69,83,97,111,125,140,238$ \\
\hline 12 & 5-Octadecene & 1789 & $43,55,69,83,97,111,125,139,166,180,195,224,252$ \\
\hline 13 & n-Octadecane & 1800 & 254 \\
\hline 14 & 9-Nonadecene & 1875 & $43,55,69,83,97,111,125,139,153,167,238,266$ \\
\hline 15 & $n$-Nonadecane & 1900 & 268 \\
\hline 16 & $n$-Eicosane & 2000 & 282 \\
\hline 17 & $n$-Heneicosane & 2100 & 296 \\
\hline 18 & 1-Docosene & 2195 & $43,57,69,83,97,111,125,280,308$ \\
\hline 19 & $n$-Docosane & 2200 & 310 \\
\hline 20 & $(Z)-9$-Tricosene & 2270 & $43,55,69,83,97,111,125,139,153,223,237,294,322$ \\
\hline 21 & $n$-Tricosane & 2300 & 324 \\
\hline 22 & Unidentified & & \\
\hline 23 & 1-Tetracosene & 2396 & $43,57,69,85,97,113,309,338$ \\
\hline 24 & $n$-Tetracosane & 2400 & 338 \\
\hline 25 & Cyclotetracosane & 2445 & $43,57,69,83,97,111,125,139,153,207,392$ \\
\hline 26 & 9-Pentacosene & 2465 & $43,57,69,85,97,113,141,169,197,326,350$ \\
\hline 27 & (Z)-12-Pentacosene & 2500 & 352 \\
\hline 28 & $n$-Pentacosane & 2496 & $43,57,69,83,97,125,236,257,290,322,350$ \\
\hline 29 & 1-Hexacosene & 2593 & $43,57,69,83,97,111,125,139,336,364$ \\
\hline 30 & $n$-Hexacosane & 2600 & 366 \\
\hline 31 & $n$-Heptacosane & 2700 & 380 \\
\hline 32 & $n$-Octacosane & 2800 & 394 \\
\hline 33 & Squalene & 2663 & $41,55,69,81,95,109,121,136,148,341,367,410$ \\
\hline 34 & $n$-Nonacosane & 2900 & 408 \\
\hline 35 & $n$-Hentriacontane & 3100 & 436 \\
\hline
\end{tabular}

${ }^{\mathrm{a}}$ No $=$ Peak numbers referring to Fig. 2

${ }^{\mathrm{b}} R I$ Retention Index 